Check for updates

Cite this: J. Mater. Chem. A, 2020, 8 , 20037

Received 3rd June 2020

Accepted 2nd September 2020

DOI: $10.1039 / d 0 t a 05583 b$

rsc.li/materials-a

\section{Novel laser-assisted glass frit encapsulation for long-lifetime perovskite solar cells $\uparrow$}

\author{
Jorge Martins, (D) $\ddagger^{a}$ Seyedali Emami, (D) $\ddagger^{a}$ Rúben Madureira, (D) ab \\ Joaquim Mendes, (D) bc Dzmitry Ivanou (iD) *a and Adélio Mendes (D) *a
}

\begin{abstract}
Hermetic encapsulation protects perovskite solar cells (PSCs) from degradations induced by humidity and oxygen. A novel dual laser beam glass frit sealing process is developed and optimized to hermetically encapsulate PSCs. A 3D transient phenomenological model of the laser-assisted encapsulation is developed, validated and used to optimize the glass sealing procedure. During the laser-sealing process, the cells are subjected to $65 \pm 5{ }^{\circ} \mathrm{C}$ for a short time of $<60 \mathrm{~s}$. This extremely low process temperature glass sealing procedure is applied to encapsulate $n-i-p$ PSCs fabricated with a poly[bis(4-phenyl)(2,4,6trimethylphenyl)amine] (PTAA) hole transport layer ( $\mathrm{HTL}$ ). The long-term stability of the encapsulated PSCs is examined under elevated humidity conditions and by thermal cycling tests. No performance variations after $500 \mathrm{~h}$ of humidity aging at $85 \% \mathrm{RH}$ and 50 thermal cycles of $-40{ }^{\circ} \mathrm{C}$ to $65^{\circ} \mathrm{C}$ are observed. Though a $16 \%$ PCE loss is observed after thermal cycles between $-40{ }^{\circ} \mathrm{C}$ and $85{ }^{\circ} \mathrm{C}, \mathrm{XRD}$ analysis revealed no perovskite decomposition and the performance losses are assigned to the thermal degradation of the HTL material. A hermetic encapsulation is a critical step for the transition of PSCs from the laboratory to the market and this glass encapsulation ensures a successful path towards the commercialization of these emerging PV devices.
\end{abstract}

\section{Introduction}

First reported in 2009, perovskite solar cells (PSCs) reached in a decade a power conversion efficiency (PCE) of $25.2 \% .^{1,2}$ PSCs are now entering into direct competition with commercial photovoltaics. However, the long-term stability of PSCs is still a challenge to overcome. ${ }^{3}$ The stability of PSCs is affected by exposure to moisture, oxygen, heat and UV light. ${ }^{4}$

PSCs are typically fabricated on glass substrates coated with a transparent conductive oxide (TCO) and comprise several layers: an electron transport layer (ETL); a mesoporous scaffold; the perovskite light absorber; a hole transport layer (HTL); and a back contact. ${ }^{3}$ Organometallic halides are the most common light absorbers in PSCs and methylammonium (MA) lead iodide is the most frequently used one. ${ }^{4}$ Upon exposure to moisture $\mathrm{MAPbI}_{3}$ vigorously decomposes to MAI and $\mathrm{PbI}_{2}$. The

\footnotetext{
${ }^{a} L E P A B E$ - Laboratory for Process Engineering, Environment, Biotechnology and Energy, Faculty of Engineering, University of Porto, Rua Dr. Roberto Frias, 4200-465 Porto,Portugal.E-mail:mendes@fe.up.pt; ivanou@fe.up.pt

${ }^{b} I N E G I$ - Institute of Science and Innovation in Mechanical and Industrial Engineering, Faculty of Engineering, University of Porto, Rua Dr. Roberto Frias, 4200-465 Porto, Portugal

${ }^{c}$ FEUP - Faculty of Engineering, University of Porto, Rua Dr. Roberto Frias, 4200-465 Porto, Portugal

$\dagger$ Electronic supplementary information (ESI) available. See DOI: 10.1039/d0ta05583b

\$ These authors contributed equally to this work.
}

degradation rate is faster when other factors such as heat and light are combined with moisture., ${ }^{4,5}$

Performance losses due to oxygen exposure occur predominantly under UV light when $\mathrm{TiO}_{2}$ is used as an ETL and scaffold. ${ }^{6}$ Surface defects on $\mathrm{TiO}_{2}$ create trapping sites where oxygen is adsorbed, hindering charge transport. In addition, under UV light oxygen radicals are formed, causing degradation of the organic layers of the cell. ${ }^{7}$ To protect the PSC device from oxygen induced UV radiation effects, UV filter masks can be used or the $\mathrm{TiO}_{2}$ layers can be replaced by other n-type semiconductors such as $\mathrm{ZnO}$ or $\mathrm{SnO}_{2}{ }^{8}$

An air-tight encapsulation protects PSCs from moisture and oxygen ingression ${ }^{7}$ and it is a critical aspect towards the industrialization of PSCs. ${ }^{9}$ The hermeticity of an encapsulation is categorized into two groups, depending on the size of their leak channels: gross and fine leaks. Leak rates are normally presented in atm $\mathrm{cm}^{3} \mathrm{~s}^{-1}$; values above $1 \times 10^{-5}$ atm $\mathrm{cm}^{3} \mathrm{~s}^{-1}$ are considered as gross leaks. Fine leaks, in turn, are divided into: (i) non-hermetic with leak rates between $1 \times 10^{-5} \mathrm{~atm} \mathrm{~cm}^{3}$ $\mathrm{s}^{-1}$ to $1 \times 10^{-7}$ atm $\mathrm{cm}^{3} \mathrm{~s}^{-1}$ and (ii) hermetic, with values below $1 \times 10^{-7}$ atm cm $\mathrm{cm}^{-1}$. A detailed description of leak rates can be found elsewhere..$^{\mathbf{1 0 , 1 1}}$ MIL-STD-883 describes the methods for leak rate measurements of electronic devices. ${ }^{12}$

The long-term stability of PSCs is affected by two types of factors: (i) external environmental (i.e. humidity, oxygen and temperature) and (ii) operational (i.e. illumination and electrical load). The external environmental stability of a PSC is 
guaranteed through application of a hermetic encapsulation to a thermally stable cell. The operational stability is based on the properties of the device materials and interfaces, which should be resistant to illumination and electrical bias. The most frequently used tests for assessing the long-term stability of PV devices are described in International Electrotechnical Commission (IEC) standards. Recently, an extensive multiauthored study ${ }^{\mathbf{1 3}}$ suggested that IEC protocols are not suitable for PSCs. For IEC protocols the cells are required to retain 95\% of their initial PCE after the stability tests, which is challenging for PSCs. Therefore, the authors suggested to use a set of test protocols defined by the International Summit on Organic Photovoltaic Stability (ISOS) for the examination of PSCs. The ISOS procedures are based on reporting the time required for the PCE of the cell to decay from its initial value to $80 \% .^{13}$

The external environmental factors of PSCs can be examined by either IEC or ISOS tests. However, the operational stability of PSCs characterized using ISOS protocols provides better insight concerning the degradation route of the cells. For encapsulation studies, the IEC 61215 standard test protocol is the most suitable procedure. The accelerated aging test methods described in IEC standards are intended to ensure $>20$ years of lifetime for a PV device. The simulated environmental tests for the longterm stability of PV devices include damp heat, thermal and humidity-freeze cycles. ${ }^{14}$ A long-term stable encapsulation must retain its hermeticity after these tests.

The most commonly used encapsulations for PSCs are UV and thermal cure epoxy resins. ${ }^{15}$ These materials are neither hermetic nor long-term stable. The most effective reported encapsulation for PSCs uses a wide width $(15 \mathrm{~mm})$ sealant made of ethylene vinyl acetate (EVA) and "ENLIGHT" polyolefin. ${ }^{16}$ Although organic based sealants may be able to provide relatively good short-term stability, their robustness lifetime of 20 years is a challenge which needs to be discovered in real outdoor tests.

In contrast, glass frit encapsulation is known to display excellent long lifetime hermetic encapsulation characteristics. ${ }^{17}$ Glass frits are inert materials composed of low melting point glass particles with high wettability to most surfaces. ${ }^{18}$ The outstanding hermeticity and robustness of these materials make them unique where a narrow width sealant perimeter is desired. ${ }^{19}$ Glass frits are used to encapsulate several types of devices such as micro-electromechanical systems (MEMSs), ${ }^{20,21}$ organic light-emitting devices (OLEDs), ${ }^{22}$ perovskite solar cells ${ }^{\mathbf{1 1}}$ and dye-sensitized solar cells (DSSCs). ${ }^{23,24}$

The thermo-compression technique is the conventional method to perform glass frit bonding. In this process the bonding is achieved by heating the device under mechanical load up to the melting temperature of the glass frit, typically higher than $380{ }^{\circ} \mathrm{C}$, for several minutes. ${ }^{18}$ Temperature sensitive devices, such as PSCs, cannot be sealed using this approach. The perovskite light absorber and the HTL are the two most temperature sensitive components of a PSC; the $\mathrm{MAPbI}_{3}$ light absorber is thermally stable up to $120{ }^{\circ} \mathrm{C}$ (ref. 25) and the most common HTLs, 2,2',7,7'-tetrakis( $N, N$-di- $p$-methoxyphenylamine)-9,9'-spirobifluorene (spiro-OMeTAD) and poly[bis(4- phenyl)(2,4,6-trimethylphenyl)amine] (PTAA) show thermal degradation at $70{ }^{\circ} \mathrm{C}$ and $85{ }^{\circ} \mathrm{C}$, respectively. ${ }^{26-28}$

Laser-assisted glass frit bonding is an alternative method to thermo-compression. ${ }^{23}$ This technique uses a laser beam to locally heat the glass frit material to its melting temperature, while the entire device is kept at lower processing temperature. ${ }^{29}$ During laser bonding, the generated thermal gradient causes mechanical stress on the encapsulation package. Thus, an external heating source (e.g. a hot plate or a furnace) is used to reduce the stress on the device. ${ }^{30}$ The process temperature of the laser-assisted method is defined by the temperature provided by the external heating source and the dwell time is the duration that the device is exposed to heat. To date, the reported process temperature for glass frit laser-assisted bonding ranges from $100{ }^{\circ} \mathrm{C}$ to $330{ }^{\circ} \mathrm{C}$ for a dwell time of $35 \mathrm{~min}$ to 3 hours. ${ }^{11,23}$

The most highlighted advantage of glass frit encapsulation is its high durability and hermeticity. The laser-assisted method of glass frit bonding allows utilization of the mentioned advantages in PSCs where a low processing temperature and short dwell time are required. A robust and hermetic encapsulation is essential for the future industrialization of PSC devices.

We have recently reported an encapsulation method for HTL-free PSCs using the laser-assisted glass frit technique. The PSCs were encapsulated at a process temperature of $100{ }^{\circ} \mathrm{C}$ for a dwell time of $35 \mathrm{~min}$, the maximum thermal operating conditions allowed by a perovskite absorber. ${ }^{11}$ The laser-assisted glass frit encapsulation effectively prevented PSCs from being effected by external environmental instability factors of humidity and oxygen. However, to encapsulated conventional $n-\mathrm{i}-\mathrm{p}$ PSCs containing HTLs, the process temperature and dwell time must be reduced. The present work describes a novel dual laser beam encapsulation approach to encapsulate temperature sensitive HTL-based conventional n-i-p PSCs at $65{ }^{\circ} \mathrm{C} \pm 5{ }^{\circ} \mathrm{C}$ with a dwell time of $<60 \mathrm{~s}$. The developed technique extends the applicability and advantages of glass frit encapsulation to all PSC device structures.

\section{Materials and methods}

\subsection{Device preparation}

The FTO layer on the glass substrates $\left(1.1 \mathrm{~mm}, 10 \Omega \square^{-1}\right.$ from VisionTek Systems Ltd.) was chemically etched to separate front and back contacts. The substrates were then ultrasonically washed with detergent and distillated water, respectively. After drying the glass substrates were treated with a UV-ozone cleaner for $20 \mathrm{~min}$. The $\mathrm{TiO}_{2}$ compact layer was deposited by spray pyrolysis at $450{ }^{\circ} \mathrm{C}$ using a precursor solution of titanium diisopropoxide bis(acetylacetonate) in anhydrous 2-propanol, followed by a 45 min sintering step. The mesoporous $\mathrm{TiO}_{2}$ layer was then deposited by spin coating for $10 \mathrm{~s}$ at $5000 \mathrm{rpm}$ with a ramp rate of $2000 \mathrm{rpm} \mathrm{s}^{-1}$, using a $30 \mathrm{~nm}$ particle paste (Greatcell Solar 30 NR-D) diluted in ethanol with a mass concentration of $1: 6$. After the spin coating, the substrates were dried at $100{ }^{\circ} \mathrm{C}$ for $10 \mathrm{~min}$ and sintered at $500{ }^{\circ} \mathrm{C}$ for 30 min. For the deposition of this layer, the cell substrate was 
masked with Kapton tape from 3M, which was removed before the sintering step.

A $28 \mathrm{~mm}$ diameter circle shape of glass frit A was then screen printed on the device substrate with a linewidth of $4 \mathrm{~mm}$ and sintered at $500{ }^{\circ} \mathrm{C}$. A second glass frit (glass frit B) with a linewidth of $1 \mathrm{~mm}$ was then screen printed on top of the first glass frit (glass frit A) and sintered at $400{ }^{\circ} \mathrm{C}$. A third glass frit (glass frit C) with a $28 \mathrm{~mm}$ diameter circle shape and a linewidth of 1 $\mathrm{mm}$ was screen printed on the cover glass substrate and sintered at $450{ }^{\circ} \mathrm{C}$.

The perovskite solution was prepared by mixing a precursor solution of formamidinium iodide (FAI, $1 \mathrm{M})$, lead iodide $\left(\mathrm{PbI}_{2}\right.$, $1.1 \mathrm{M}$ ), methylammonium bromide ( $\mathrm{MABr}, 0.2 \mathrm{M})$ and lead bromide $\left(\mathrm{PbBr}_{2}, 0.2 \mathrm{M}\right)$ in a mixture of anhydrous $\mathrm{N}, \mathrm{N}$-dimethylformamide/dimethyl sulfoxide (DMF : DMSO, $4: 1 \mathrm{v} / \mathrm{v}$ ). The dual cation perovskite precursor was then mixed with $5 \mathrm{wt} \%$ cesium iodide (CsI, $1.5 \mathrm{M}$ in DMSO) to prepare a $\mathrm{Cs}_{0.05}\left(\mathrm{MA}_{0.17^{-}}\right.$ $\left.\mathrm{FA}_{0.83}\right)_{0.95} \mathrm{~Pb}\left(\mathrm{I}_{0.83} \mathrm{Br}_{0.17}\right)_{3}$ triple cation perovskite precursor solution. Before the deposition of the perovskite and HTL layers, the cell substrate was masked with Kapton tape to protect the glass frits and contacts from contamination. The perovskite layer was spin coated for $10 \mathrm{~s}$ at $1000 \mathrm{rpm}$, followed by $30 \mathrm{~s}$ at $6000 \mathrm{rpm} ; 15$ $\mathrm{s}$ before the end of the second step, an anti-solvent (chlorobenzene) was dropped on the spinning substrate. The substrates were then annealed at $100{ }^{\circ} \mathrm{C}$ for $40 \mathrm{~min}$. After annealing, the substrates were cooled down to room temperature before the deposition of the HTL. A solution of PTAA (Ossila) (10 $\mathrm{mg} \mathrm{mL}^{-1}$ ) in toluene was prepared and doped with $1.6 \mu \mathrm{L}$ of bis(trifluoromethylsulfonyl)imide lithium solution (Li-TFSI, SigmaAldrich) $(1.8 \mathrm{M})$ in acetonitrile and $2 \mu \mathrm{L}$ of 4-tert-butylpyridine ( $t \mathrm{BP}$, Acros Organic, 96\%). The PTAA solution was then spincoated at $4000 \mathrm{rpm}$ for $20 \mathrm{~s}$. Then, the Kapton mask was removed and a new Kapton mask was used to pattern the device for gold back contact deposition. A gold back contact of $60 \mathrm{~nm}$ was deposited by thermal evaporation. A schematic diagram of the device preparation is illustrated in Fig. S1 (ESI $\dagger$ ). As shown in Fig. S1,$\dagger$ the charge collection of both front and back contacts of the PSC devices is through the FTO layer of the substrate and no additional current collectors were used.

\subsection{Sealing procedure}

A multi-layer glass frit configuration comprising three glass frits was used to encapsulate the devices. The triple layer structure includes glass frits A and B on the device glass substrate and glass frit $\mathrm{C}$ on the cover glass. After sintering, the thicknesses of glass frits A, B and C are $c a .17 \mu \mathrm{m}, 22 \mu \mathrm{m}$ and $13 \mu \mathrm{m}$, respectively. Each glass frit layer plays a specific role during laserassisted sealing; a detailed description of the triple layer glass frit configuration can be found elsewhere. ${ }^{11}$ Briefly, in this sealant configuration $(\mathrm{AB}-\mathrm{C})$ the bonding is achieved by joining glass frit B to glass frit $\mathrm{C}$. Glass frit $\mathrm{C}$ with high ductility and thermal conductivity serves for dissipating the thermal stresses build up at the cover glass when laser radiation is absorbed. Glass frit B, with a low melting temperature, is used to achieve the bonding at $c a .380^{\circ} \mathrm{C}$. Glass frit A minimizes the thermal stress on the device glass substrate.
The laser-assisted glass frit encapsulation was performed using an in-house made apparatus named "LaserStation" described elsewhere. ${ }^{30}$ This equipment was modified to accomplish sealing experiments using two laser beams. The upgraded system comprises two $1070 \mathrm{~nm}$ continuous wave (CW) laser sources with a maximum output of $100 \mathrm{~W}$ and $200 \mathrm{~W}$ and two optics sets of 2D scan head/f-theta lens, one for each laser source. A four-axis Selective Compliance Assembly Robot Arm (SCARA) is used to position the optics sets above the workpiece. A furnace with a glass lid transparent at the laser beam wavelength is used as an external heating source - Fig. S2. $\dagger$

Samples were prepared by sandwiching the bottom (cell) and top (cover) substrates together, in such a way that sealant lines of glass frits C and B are aligned. The prepared device is then placed inside a furnace at $50{ }^{\circ} \mathrm{C}$ and maintained for $60 \mathrm{~min}$, for temperature stabilization before performing the laser-sealing process. The SCARA arm aligns the optic sets with the sealant perimeter and during laser bonding the laser beams are focused on the glass frit C with a spot size of $c a .0 .6 \mathrm{~mm}$.

\subsection{Stability tests}

Humid air exposure and thermal cycling tests were performed on the encapsulated PSC devices. For humid air exposure, the samples were stored in a $17.5 \times 17.5 \times 6 \mathrm{~cm}^{3}$ stainless steel chamber and submitted to a humidified air flow. The humid air was produced by feeding $200 \mathrm{~mL} \mathrm{~min}{ }^{-1}$ dry air through a cylindrical column filled with distilled water. The humidity level inside the chamber was measured using a humidity sensor and kept at $c a$. $85 \%$ relative humidity (RH). The mentioned test was performed at room temperature $\left(\mathrm{ca} .20^{\circ} \mathrm{C}\right)$ for 500 hours. The thermal cycling test was carried out inside an industrial climatic chamber (Fitoclima; Aralab). Two climatic simulated tests were performed; (i) 50 thermal cycles from $-40{ }^{\circ} \mathrm{C}$ to $85{ }^{\circ} \mathrm{C}$, according to IEC 61215 (ref. 14) and (ii) 50 cycles from $-40{ }^{\circ} \mathrm{C}$ to $65{ }^{\circ} \mathrm{C}-$ Fig. S3. $\dagger$ The heating/ cooling rate was $1^{\circ} \mathrm{C} \mathrm{min}^{-1}$ and each cycle had a $10 \mathrm{~min}$ dwell time at maximum and minimum temperatures.

\subsection{Device characterization}

The photocurrent-potential $(J-V)$ curves were recorded with an electrochemical workstation (Zahner; Zennium) by applying an external potential bias in a reverse scan mode with a rate of 10 $\mathrm{mV} \mathrm{s}^{-1}$. The masked cells ( $c a .0 .2 \mathrm{~cm}^{2}$ active area) were measured using an Oriel class ABA LED solar simulator (MiniSol LSH 732; Newport) calibrated for AM1.5G illumination of $100 \mathrm{~mW} \mathrm{~cm}{ }^{-2}$. The optical reflectance spectra of the cells were recorded with a UV-VIS-NIR spectrophotometer (Shimadzu UV3600). The XRD spectra were obtained with a Siemens D5000 Xray diffractometer ( $\mathrm{Cu} \mathrm{K} \alpha$ radiation).

\section{Results and discussion}

\subsection{Phenomenological simulation-based optimization of the laser-assisted encapsulation}

Our previous study showed that laser-assisted glass frit encapsulation can be achieved at a process temperature of $100{ }^{\circ} \mathrm{C}$, using a single laser beam and a glass frit with a bonding 
temperature of $380{ }^{\circ} \mathrm{C}$. The objective of the present work is to reduce the process temperature to $c a .50{ }^{\circ} \mathrm{C}$ for achieving glass frit encapsulation compatible with $n-\mathrm{i}-\mathrm{p}$ temperature-sensitive PSCs.

During laser-assisted sealing, the glass frits and glass substrates are locally heated up from the process temperature ( $\left.T_{\text {process }}\right)$ to the bonding temperature $\left(T_{\text {bonding }}\right)$; after the sealing is accomplished, the temperature relaxes from $T_{\text {bonding }}$ to $T_{\text {process. }}$ The minimum laser added temperature to accomplish the sealing is defined as $T_{\mathrm{LA}}=T_{\text {bonding }}-T_{\text {process }}$. The temperature changes induce stresses in both glass substrates and glass frits. Stress may be generated due to the coefficient of thermal expansion (CTE) differences at the substrate/glass frit interface or due to the thermal gradient along the bodies of the substrates or the glass frits. Excessive stress causes defects such as cracks and delamination. Defects produced during and after lasersealing are caused by thermal or residual stresses, respectively. To minimize the thermal stress of a very high laser added temperature, $T_{\mathrm{LA}}=330{ }^{\circ} \mathrm{C}$, two approaches were considered: (i) using a second laser to locally increase the temperature of the sealant for a short dwell time and (ii) using glass substrates of different thicknesses.

In dual laser beam configuration (Fig. 1), one laser beam $\left(\mathrm{LB}_{\text {heat }}\right)$ is used to locally heat the sealant material from the process temperature of $50{ }^{\circ} \mathrm{C}$ to the operating temperature of 100-120 ${ }^{\circ} \mathrm{C}$ for a short time of $<2 \mathrm{~min}$, while the other laser beam ( $\mathrm{LB}_{\text {bond }}$ ) is used to achieve the bonding temperature $c a$. $380{ }^{\circ} \mathrm{C}$ ( $\left.T_{\text {bonding }}\right)$. $\mathrm{LB}_{\text {heat }}$ scans the entire sealant perimeter at a fast scanning velocity $\left(4000 \mathrm{~mm} \mathrm{~s}^{-1}\right)$. $\mathrm{LB}_{\text {bond }}$ moves at a slower scanning velocity of $210 \mathrm{~mm} \mathrm{~s}^{-1}$ along the sealing line to bond the substrates.

The laser-sealing process was simulated by finite element methods. The heat transfer at the encapsulation components, i.e. glass frit layers and glass substrates, during the laser-sealing process is a $3 \mathrm{D}$-transient thermal phenomenon which can be described by Fourier's Law (eqn (S1) $\dagger$ ). ${ }^{31}$ The coupled thermoelastic-plastic (eqn $(\mathrm{S} 2) \dagger$ ) differential equations describe the stress and strain distribution at the encapsulation components. ${ }^{32}$ Ansys Mechanical 2020 software was used to solve the model (see the ESI† for description).

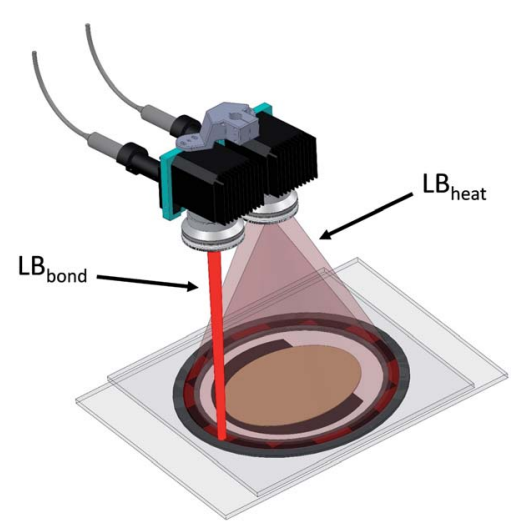

Fig. 1 Scheme of the laser-assisted glass frit sealing process with dual laser beam configuration.
3 different operating conditions were analyzed assuming glass substrates of $1.1 \mathrm{~mm}$ and of $2.2 \mathrm{~mm}$ thickness: (a) furnace temperature of $50{ }^{\circ} \mathrm{C}$ with single laser beam heating $\left(T_{\mathrm{LA}}=330\right.$ ${ }^{\circ} \mathrm{C}$ ); (b) furnace temperature of $110{ }^{\circ} \mathrm{C}$ with single laser beam heating $\left(T_{\mathrm{LA}}=270{ }^{\circ} \mathrm{C}\right)$; (c) furnace temperature of $50{ }^{\circ} \mathrm{C}$ with local heating $\left(\mathrm{LB}_{\text {heat }}\right)$ of the glass frit to the operating temperature of $100-120^{\circ} \mathrm{C}$ (dual laser beam configuration, $T_{\mathrm{LA}}=330$ ${ }^{\circ} \mathrm{C}$ ).

Fig. 2 shows the model results for the maximum stress observed in the substrates during the laser-sealing. Decreasing the furnace temperature from $110{ }^{\circ} \mathrm{C}$ to $50{ }^{\circ} \mathrm{C}$ results in increasing stress for $13.3 \%$. This trend is observed for both 1.1 $\mathrm{mm}$ and $2.2 \mathrm{~mm}$ glass substrates. Local heating of the glass frit from the furnace temperature of $50{ }^{\circ} \mathrm{C}$ to the operating temperature of $110 \pm 10{ }^{\circ} \mathrm{C}$, using a secondary laser beam, decreases the stress by $10.2 \%$ for the $2.2 \mathrm{~mm}$ substrates and by $8 \%$ for the $1.1 \mathrm{~mm}$ glass substrates. Thus, the dual laser beam configuration plays a considerable role in reducing the thermal stresses.

Reducing the glass substrate thickness from $2.2 \mathrm{~mm}$ to 1.1 $\mathrm{mm}$ decreases the stress for all studied operating conditions, $15.5 \%$ for the case of furnace temperature of $50{ }^{\circ} \mathrm{C}$ and $110{ }^{\circ} \mathrm{C}$, and $13.5 \%$ for the case with local secondary laser heating. Reducing the substrate thickness decreases the thermal inertia of the substrate. This means that for equal conditions, the temperature of the substrate increases faster, therefore decreasing the thermal gradient of the body for this transient situation. The simulation results clearly show that the stress on the substrates, during the laser-assisted process, can be reduced by using dual laser beam configuration and $1.1 \mathrm{~mm}$ glass substrates.

It is worth mentioning that the process temperature of $50{ }^{\circ} \mathrm{C}$ provided by the furnace reduces the stress created during the sealing process due to lowering the thermal gradient. In the dual laser beam bonding, the glass frit is heated by $\mathrm{LB}_{\text {heat }}$ to $c a$. $110^{\circ} \mathrm{C}$ while the glass substrates are at the furnace temperature of $50{ }^{\circ} \mathrm{C}$. For the case of $1.1 \mathrm{~mm}$ thick glass substrates, the increase in the process temperature from $25{ }^{\circ} \mathrm{C}$ (room temperature) to $50^{\circ} \mathrm{C}$ reduces the stress on the glass substrates from 62

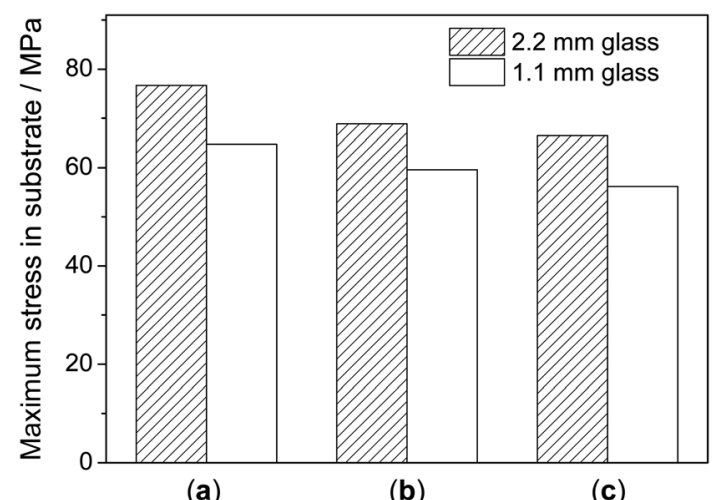

Fig. 2 Maximum stress for $2.2 \mathrm{~mm}$ and $1.1 \mathrm{~mm}$ glass substrates for: (a) furnace temperature of $50{ }^{\circ} \mathrm{C}$; (b) furnace temperature of $50{ }^{\circ} \mathrm{C}$ and local secondary laser heating to the operating temperature of $110 \pm 10$ ${ }^{\circ} \mathrm{C}$ and; (c) furnace temperature of $110^{\circ} \mathrm{C}$. 
MPa to 59.6 MPa. In addition, since glass is a very low thermal conductive material $\left(1.05 \mathrm{~W} \mathrm{~m}^{-1} \mathrm{~K}^{-1}\right)$, prolonging the heating period is necessary for the glass substrates to achieve thermal equilibrium. Our previous study ${ }^{29}$ showed that the process temperature provided by the furnace requires $60 \mathrm{~min}$ to achieve a homogenous temperature on the device. Therefore, for the present work the samples were heated in the furnace at $50{ }^{\circ} \mathrm{C}$ for $60 \mathrm{~min}$ before the laser-sealing process.

The simulated temperature profiles for the glass frits and substrates during the dual laser beam sealing of $1.1 \mathrm{~mm}$ glass are presented in Fig. 3a. Fig. S4 and Media $\mathrm{S} 1 \dagger$ show the simulated temperatures in the cross section of the glass frit and substrates during the laser-sealing process. The laser-sealing process can be divided into 5 steps: (I) the device is placed in the furnace at the process temperature of $50{ }^{\circ} \mathrm{C}$ until a homogeneous temperature is reached (the temperature stabilization period is not represented) - Fig. $\mathrm{S} 4 \mathrm{a}$; $\uparrow$ (II) $\mathrm{LB}_{\text {heat }}$ radiates and the sealant temperature increases up to $110 \pm 10^{\circ} \mathrm{C}-$ Fig. $\mathrm{S} 4 \mathrm{~b} ; \dagger$ (III) $\mathrm{LB}_{\text {bond }}$ is emitted, raising the temperature in the glass frit up to $>380{ }^{\circ} \mathrm{C}$, bonding the substrates - Fig. $\mathrm{S} 4 \mathrm{c} ; \dagger$ (IV) $\mathrm{LB}_{\text {bond }}$ is turned off and $\mathrm{LB}_{\text {heat }}$ continues emitting, maintaining the sealant material at $110 \pm 10^{\circ} \mathrm{C}-$ Fig. S4d-f; $\dagger$ (V) laser-sealing finishes, $\mathrm{LB}_{\text {heat }}$ is turned off and the temperature in the sealant decreases to the process temperature - Fig. S4g and h. $\dagger$ The mentioned 5 steps are illustrated in Fig. 3.

The heat affected zone (HAZ) of $\mathrm{LB}_{\text {heat }}$ may cause thermal damage to the active layers of the PSC device. Although the dwell time of this heating is shorter than $120 \mathrm{~s}$, the heat flows inward the cell, reaching the device active layers mainly through the bottom glass substrate. The temperature profiles in the cell substrate, bottom glass substrate, at different distances from the center of the glass frit are presented in Fig. 3b. These simulated data are particularly important to establish a safe

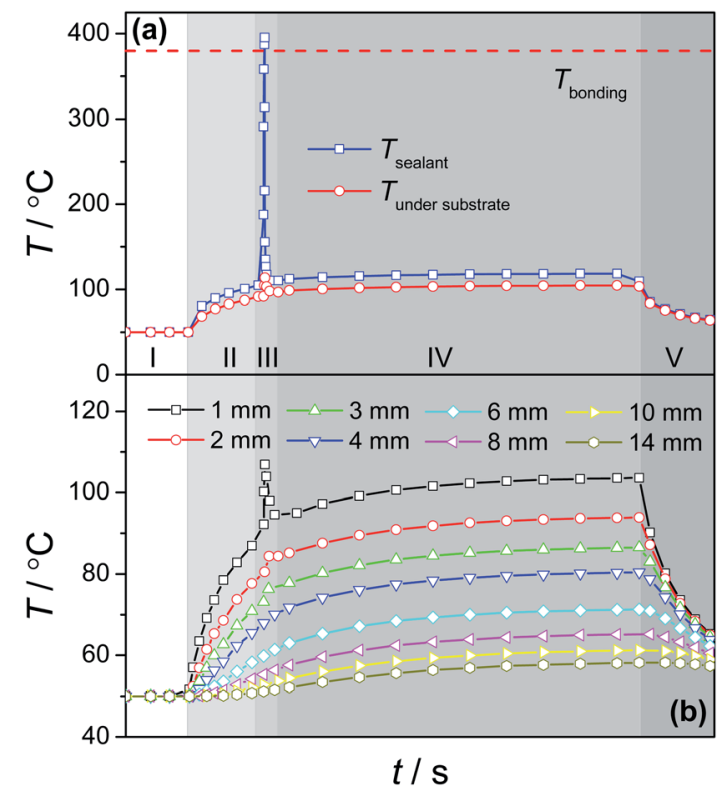

Fig. 3 Simulated temperature profiles for the (a) sealant and at the rear side of the cell substrate and (b) the cell substrate at 1, 2, 3, 4, 6, 8, 10 and $14 \mathrm{~mm}$ distances from the center of the glass frit. distance between the glass frit sealing line and the active layers of the PSC. At $1 \mathrm{~mm}$ from the center of the glass frit line, the cell substrate temperature reaches temperatures above $100{ }^{\circ} \mathrm{C}$, as well as being affected by $\mathrm{LB}_{\text {bond }}$. The temperature reaches a maximum value of $80{ }^{\circ} \mathrm{C}$ and $70{ }^{\circ} \mathrm{C}$, at $4 \mathrm{~mm}$ and $6 \mathrm{~mm}$ distances away from the center of the glass frit line, respectively. As mentioned before, the most temperature sensitive component of a PSC device is the HTL. The simulated results indicate that $4 \mathrm{~mm}$ away from the center of the sealing line, the temperature reaches $80{ }^{\circ} \mathrm{C}$, the thermal stability threshold at which PTAA can be used as a HTL. For the case of using spiroOMeTAD as a HTL, the safe distance should be 6 to $8 \mathrm{~mm}$. Thus, the selected HTL layer must consider the mentioned aspects to ensure suitable implementation of the laser-sealing process for the device geometry.

\subsection{Experimental validation of the laser-assisted encapsulation}

The mathematical model was validated by comparing simulated to experimental results. Fig. 4a shows the actual temperature history of the sealant for optimized sealing conditions, measured by using thermocouples. Fig. S5† illustrates the position of the thermocouples on the device. The sealing process starts when the laser $\mathrm{LB}_{\text {heat }}$ is radiated at $35 \mathrm{~W}$ with a scanning velocity of $4000 \mathrm{~mm} \mathrm{~s}^{-1}$. The temperature at the sealant gradually increases and stabilizes at $110 \pm 5{ }^{\circ} \mathrm{C}$, after $c a$. 20 seconds of laser emission. At this moment, $\mathrm{LB}_{\text {bond }}$ is emitted at $41 \mathrm{~W}$ with a scanning velocity of $210 \mathrm{~mm} \mathrm{~s}^{-1}$. The temperature of the sealant raises rapidly above $380{ }^{\circ} \mathrm{C}$, melting the glass frit and bonding the substrates. After bonding, the $\mathrm{LB}_{\text {heat }}$ power is gradually reduced, slowly decreasing the temperature of the sealant - Fig. 4c. The total laser processing time is ca. 65 seconds.

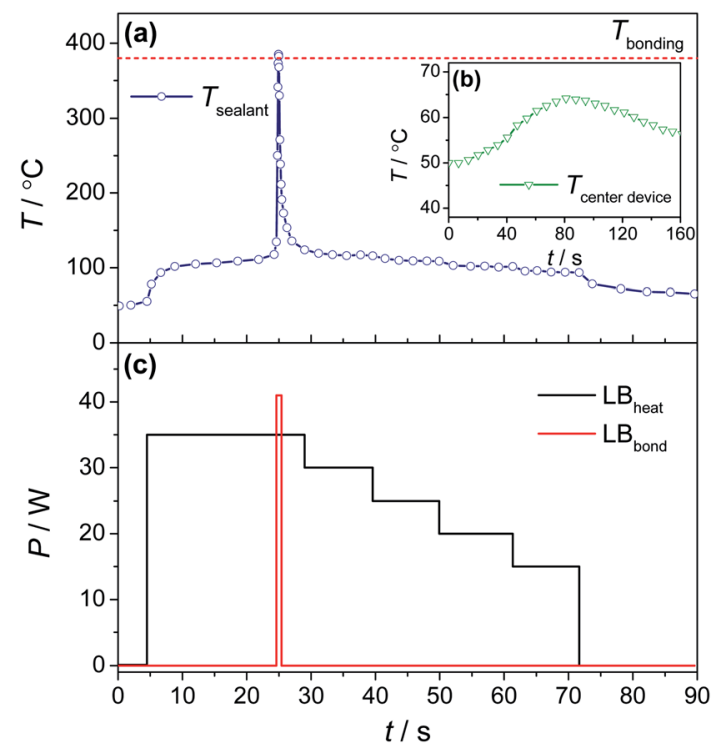

Fig. 4 Temperature history of the (a) sealant and (b) center of the cell substrate during the laser encapsulation process; (c) power timeline of the two laser beams. 
As mentioned before, the low thermal conductivity of the glass substrate is an important factor in controlling the stress during the laser-sealing process. The output power of $\mathrm{LB}_{\text {heat }}$ must be tailored not only to avoid excess stress but also excessive temperature increase at the center of the device. To balance the mentioned stress and thermal effects after the emission of $\mathrm{LB}_{\text {bond }}$, the output power of $\mathrm{LB}_{\text {heat }}$ was kept constant for a short period and then it was incrementally decreased until being switched off (Fig. 4c). This procedure allowed the reduction of the stress on the substrates and keeping the temperature of the device below the thermal decomposition of the PSC layers.

The temperature increases at the center of the device $(14 \mathrm{~mm}$ distance from the glass frit) to a maximum of $65 \pm 5{ }^{\circ} \mathrm{C}$ for a short dwell time of $<60 \mathrm{~s}-$ Fig. $4 \mathrm{~b}$. Although the simulated temperature at the center of the device was slightly lower, $c a .60$ ${ }^{\circ} \mathrm{C}$ (Fig. 3b), the experimental results show suitable agreement with the simulation. Therefore, the $4 \mathrm{~mm}$ distance from the center of the glass frit sealing line required for not reaching temperatures above $80{ }^{\circ} \mathrm{C}$, obtained by the simulation, was considered for the deposition of the PSC active layers. As predicted by the model, the screening experimental results showed that the temperatures of the laser process can cause thermal decomposition of the spiro-OMeTAD HTL, while PTAA-based HTL devices showed no performance losses. A similar thermal decomposition behavior is reported by Mesquita et al. where spiro-OMeTAD based devices presented a high irreversible performance loss when submitted to $70 \pm 5{ }^{\circ} \mathrm{C}$, while PTAAbased devices displayed only minor losses of performance. ${ }^{28}$

Fig. S6 $\uparrow$ shows the experimental temperature profile under the bottom cell substrate. During the sealing process, the temperature increase at the rear side of the cell substrate is faster for the $1.1 \mathrm{~mm}$ substrate, compared with the $2.2 \mathrm{~mm}$ substrate, thus showing the reduced thermal inertia of the thinner glass substrate.

A batch of 14 PSCs was encapsulated according to the above described process. The performances of the devices were measured before and after the sealing and are compared in Fig. 5. The average open circuit voltage $\left(V_{\text {oc }}\right)$ remained unchanged after the sealing process at $0.91 \pm 0.03 \mathrm{~V}$; the short

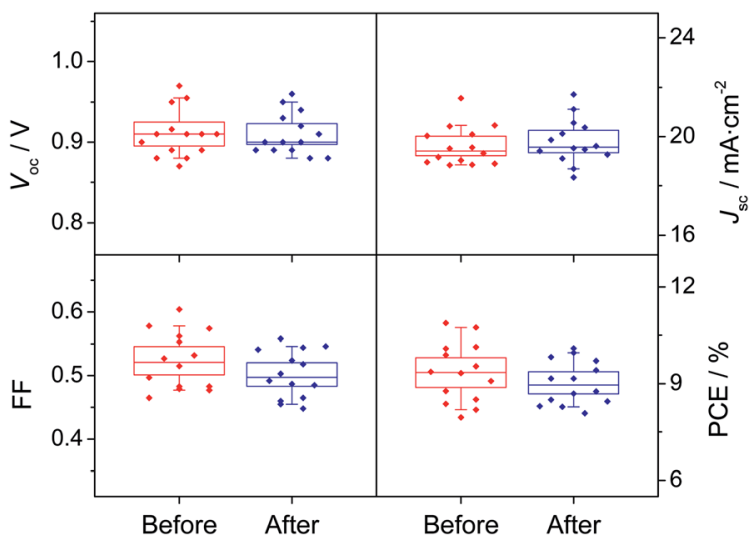

Fig. 5 Photovoltaic parameters of PSCs before and after the encapsulation process; boxes represent the standard deviation; lines show 10-90 percentile. circuit current density $\left(J_{\mathrm{sc}}\right)$ increased from $19.62 \pm 0.77 \mathrm{~mA} \mathrm{~cm}{ }^{2}$ to $19.80 \pm 0.88 \mathrm{~mA} \mathrm{~cm}^{2}$; the fill factor $(\mathrm{FF})$ decreased from 0.52 \pm 0.04 to $0.50 \pm 0.04$ and the PCE decreased from $9.35 \pm 0.89 \%$ to $9.03 \pm 0.66 \%$. The devices presented an average PCE loss of $3.4 \%$, which is a minor variation.

The focus of the present study is to develop a low temperature hermetic encapsulation process suitable to thermal sensitive conventional PSCs. Fabricating highly efficient solar cells was beyond the scope of the present study. However, the effect of incorporating the glass frit sealants into the manufacturing steps of the PSC device was studied to identify fabrication constraints and methods. As shown in Fig. S1, $\dagger$ during device preparation there are many masking steps to avoid cross contamination between layers (PSC components and glass frits). The spin-coating deposition technique requires flat and uniform substrates to achieve a high quality film..$^{33}$ Therefore, masking the substrate during the spin-coating deposition of active layers affects the quality of this deposition and namely the thickness uniformity. Three groups of PSC devices were fabricated to compare the masking and sealant effect: (i) masked with sealant (M\&S), (ii) masked without sealant (M) and (iii) no sealant and no mask (NS\&NM). There was a PCE loss of ca. $23 \%$ and $8 \%$ for M\&S and $M$ devices, when compared to the NS\&NM group - Fig. S7. $\uparrow$ The drop in PCE is due to a decrease in the $V_{\mathrm{oc}}$ for $\mathrm{M}$ devices, while for M\&S devices it is caused by a lower $V_{\mathrm{oc}}$ and FF. Lower $V_{\mathrm{oc}}$ and FF are indicators of high charge recombination caused by non-uniform films. The defects in these films create recombination sites for the generated charge at the interface between PSC layers. ${ }^{34,35}$ Therefore, the performance of the cells of the M\&S group can be improved by applying different deposition techniques such as screen printing for the mesoporous $\mathrm{TiO}_{2}$ layer and spray deposition for perovskite absorber and HTL layers. Alternatively, deposition techniques such as inkjet or slot-die should also be considered for the PSC fabrication. The mentioned improvements are beyond the scope of the present work and it can be investigated in a future study.

\subsection{Stability tests}

The main objective of the present study was to reach a low temperature laser-assisted glass frit sealing method. Therefore, the aim was to protect perovskite solar cells from humidity and oxygen degradation related factors. As mentioned before, the operational stability of PSCs under illumination and electrical bias is dependent on the device structure and interfaces. Hence, to quantify the robustness of the developed encapsulation, stability tests under harsh humidity conditions and thermal cycling were performed on the encapsulated devices. The operational stability tests are therefore beyond the scope of this work, since the objective was set to examine the hermeticity of the encapsulation towards moisture rather than the device stability towards illumination.

3.3.1. Humid air exposure. The stability of the encapsulated devices was assessed by exposing the devices to humid air ( $85 \% \mathrm{RH})$ for 500 hours. The devices were characterized during the test and the history of performance parameters is shown in 
Fig. 6a. During the humidity aging test on a batch of 6 cells, on average there was an $8.4 \%$ increase in the PCE $\left(3.2 \% V_{\text {oc }}\right.$ increase, $2.4 \% J_{\mathrm{sc}}$ decrease, and $7.5 \% \mathrm{FF}$ increase). The encapsulated devices are considered hermetic according to the MILSTD-883 standard with an average leak rate value of $1.71 \times 10^{-8}$ atm $\mathrm{cm}^{3} \mathrm{~s}^{-1}$, thereby protecting the PSC devices from moisture and oxygen exposure during the stability test. The current density $v s$. potential curve $(J-V)$ of a hermetically encapsulated cell, after $500 \mathrm{~h}$ of humid air exposure, and the $J-V$ curves before and after encapsulation are presented in Fig. $6 \mathrm{~b}$. The slight $J_{\mathrm{sc}}$ improvement after the sealing was assigned to the re-crystallization of the perovskite absorber and perovskite/HTL interface enhancement during the thermal conditioning steps of the sealing. However, the stabilized performance of the cell after the $500 \mathrm{~h}$ aging test indicates that the cells undergo various interfacial improvements to achieve better performance. A similar slight performance improvement during the aging test on sealed PSCs has been reported by other authors, ${ }^{16}$ which was assigned to a drop in the non-radiative recombination rate that causes $V_{\mathrm{oc}}$ improvement. While $J_{\mathrm{sc}}$ had a slight decrease during the aging in the hermetic device (Fig. 6), the improvement of $V_{\mathrm{oc}}$ contributes to the increase of FF and efficiency of the devices.

The effect of the hermeticity level of the glass encapsulation during the humidity aging test was studied by comparing the performance of a hermetically encapsulated device with a device with non-hermetic encapsulation - Fig. 7. The reproducibility rate for achieving a hermetic encapsulation for the dual laser-assisted sealing method of the present work is $>80 \%$. The unsuccessful encapsulation results are related to the organic contamination of the frits during spin-coating of cell layers or due to the incorrect alignment of the laser beams during sealing. These remaining $20 \%$ of the sealed samples present cracks and loss of adhesion at the interface of glass frit/ glass substrate; the hermeticity level of these devices (with no gross leaks) is considered as non-hermetic. The performance of the non-hermetic encapsulated device has dropped to $50 \%$ after $200 \mathrm{~h}$ of the aging test.

After $500 \mathrm{~h}$ of the stability test, the non-hermetic encapsulated device showed a higher optical reflectance spectrum, when compared to the hermetically encapsulated device, due to perovskite decomposition - Fig. S8. $\uparrow$ The X-ray diffraction (XRD) spectrum of the non-hermetic device displayed $\mathrm{PbI}_{2}$ and $\mathrm{PbBr}_{2}$ peaks associated with the moisture induced degradation of the perovskite absorber - Fig. 8. The reflectance spectrum and XRD pattern of a hermetically encapsulated PSC remained similar to those of a fresh fabricated device - Fig. 8 and S8. $\uparrow$ Since the XRD patterns presented in Fig. 8 are from different batches of prepared cells, few peak variations can be identified. The
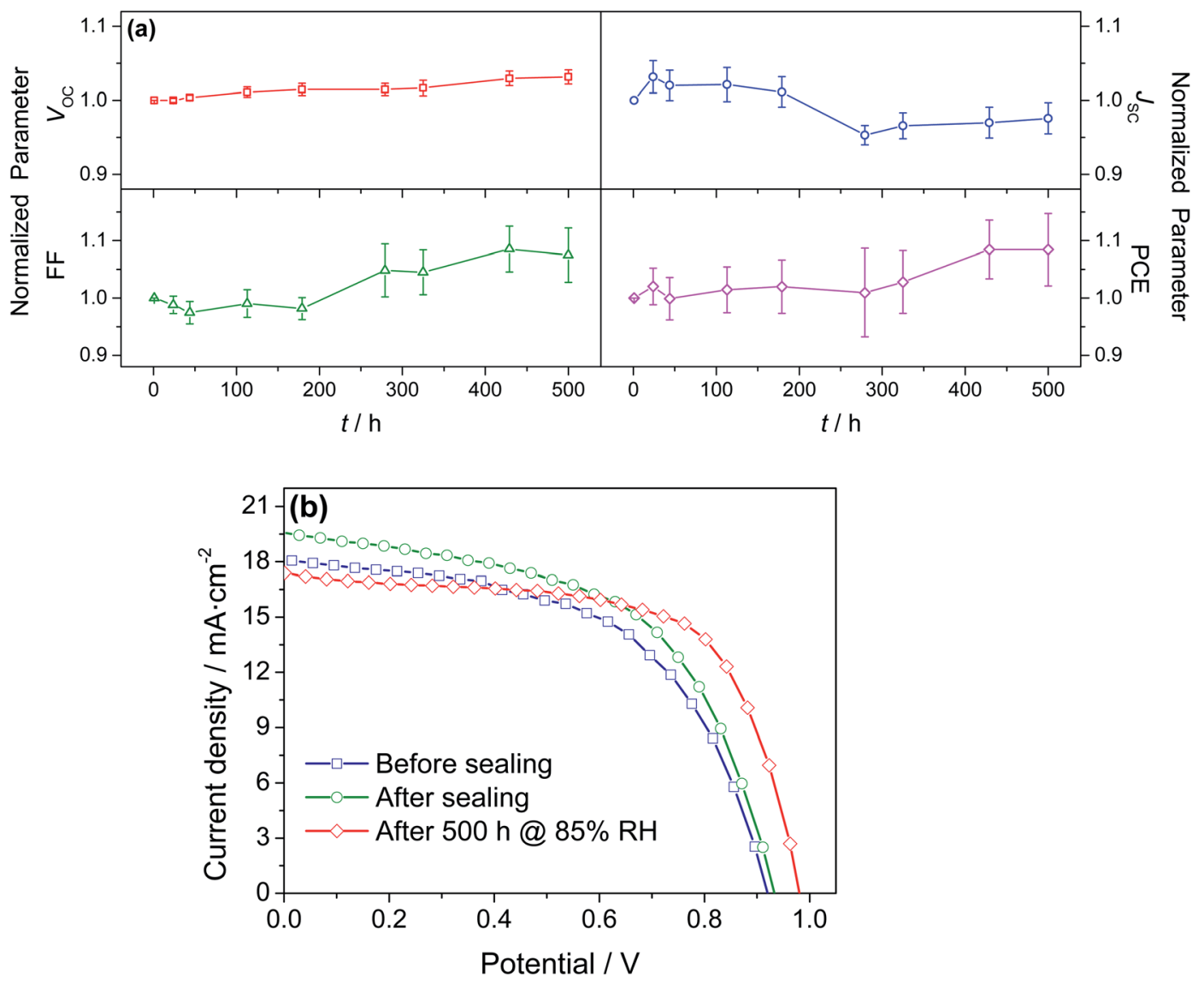

Fig. 6 (a) Normalized photovoltaic parameters of hermetically encapsulated PSCs submitted to a $500 \mathrm{~h}$ humid air exposure test; (b) current density vs. potential curves of a PSC before and after the sealing process and of a hermetically encapsulated device after $500 \mathrm{~h}$ of humid air exposure. 


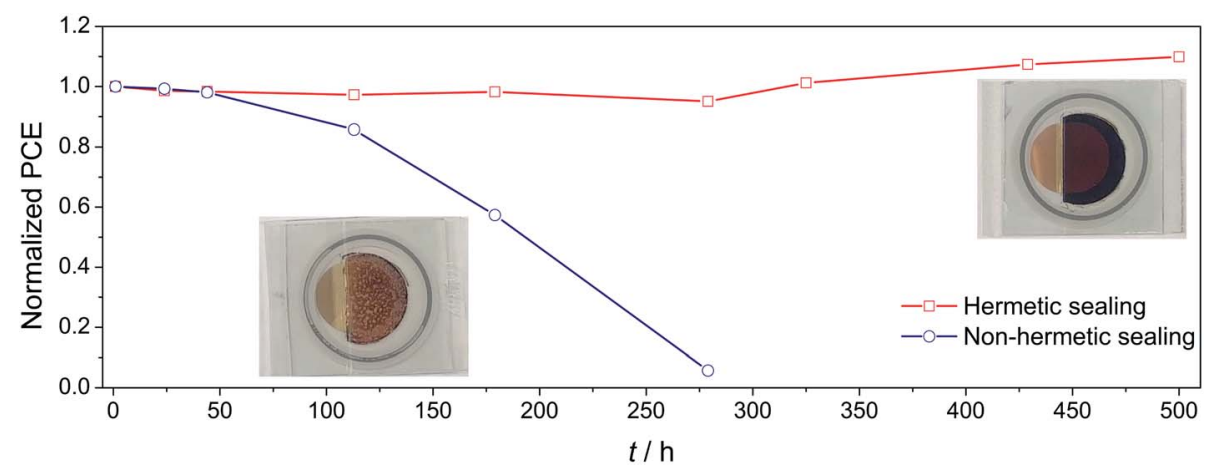

Fig. 7 Normalized PCE of devices with hermetic and non-hermetic encapsulation submitted to $500 \mathrm{~h}$ of the humid air exposure test.

reflexes associated with $\mathrm{Cs}-\mathrm{Pb}$-halide compounds for hermetically sealed devices were assigned to unreacted salts during the perovskite precursor preparation, while similar peaks are not identified for fresh devices, prepared in a different batch.

3.3.2. Thermal cycling test. Hermetically encapsulated devices were submitted to a thermal cycling test from $-40{ }^{\circ} \mathrm{C}$ to $85{ }^{\circ} \mathrm{C}$, according to the IEC 61215 standard. Although there is no humidity control during this test, RH can reach up to $85 \%$. The purpose of this standard test is to simulate the outdoor climatic conditions required to ensure the stability of more than 20 years for PV devices. The long-term stability of devices during the thermal cycling test depends on the hermeticity level of the encapsulation and the thermal stability of the solar cell components. Our previous studies showed that the hermeticity of the glass frit sealant remained unchanged after this test. ${ }^{11}$ Thus, the instability source for the PSCs during the thermal cycling test should be assigned to the thermal stability of solar cell layers.

As shown in Fig. 9, the devices display a major performance loss after 50 thermal cycles - Fig. S3. $\dagger$ There was a $28.9 \pm 4.4 \%$ decrease in the $J_{\mathrm{sc}}$ of the devices, while $V_{\mathrm{oc}}$ showed a minor improvement $(2.45 \pm 0.79 \%)$. The large drop in current density and small voltage increase cause an improvement in FF. Finally, the devices displayed a $15.46 \pm 6.54 \%$ PCE drop. Since the PCE loss is more than $5 \%$, according to the IEC standard, the longterm stability results are considered as failure.

In contrast, when a moderate number of 50 thermal cycles between $-40{ }^{\circ} \mathrm{C}$ and $65{ }^{\circ} \mathrm{C}$ were applied to examine the thermal

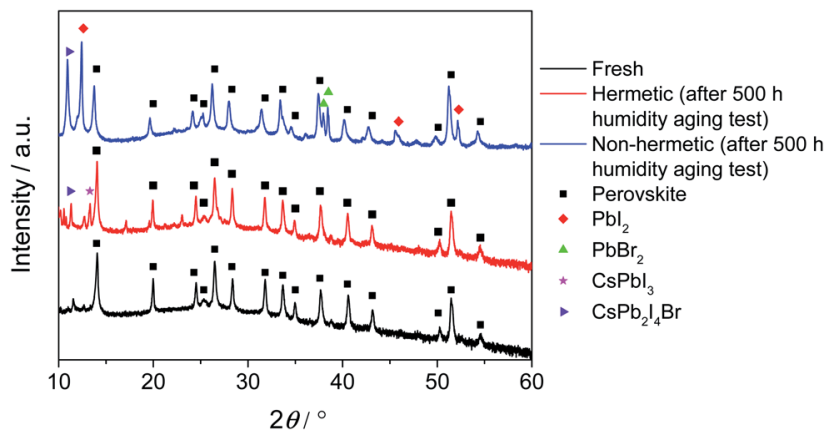

Fig. 8 XRD pattern for a fresh device, and hermetic and non-hermetic encapsulated devices after $500 \mathrm{~h}$ of the humid air exposure test. stability of the PSC components, there were no major performance variations. There was a slight increase in $V_{\text {oc }}$, while other parameters displayed minor decreases. The PCE of the devices showed a $3.06 \pm 1.89 \%$ drop, which was considered a rather small performance loss - Fig. 9.

The XRD analysis of the devices showed no onset of perovskite degradation after the $-40{ }^{\circ} \mathrm{C}$ to $85^{\circ} \mathrm{C}$ thermal cycling test Fig. 10. Therefore, the performance drop should be related to the degradation of the HTL or mechanical damages at the interface of layers due to CTE mismatch of the solar cell components. ${ }^{36}$ The results of the $-40{ }^{\circ} \mathrm{C}$ to $65{ }^{\circ} \mathrm{C}$ cycling test also indicate no thermal degradation and the XRD pattern confirms no structural changes of the perovskite absorber Fig. 10. The minor performance variation should then be assigned to minor performance degradation of the PSC active layers, which can be induced by the temperature stress as well as the mechanical stress induced by the CTE mismatch.

Similar to the humidity aging test, the effect of the hermeticity level on the encapsulation was studied for thermal cycling tests. For non-hermetic encapsulated PSCs tested in $-40{ }^{\circ} \mathrm{C}$ to $85{ }^{\circ} \mathrm{C}$ and $-40{ }^{\circ} \mathrm{C}$ to $65{ }^{\circ} \mathrm{C}$ cycling tests, the XRD analysis

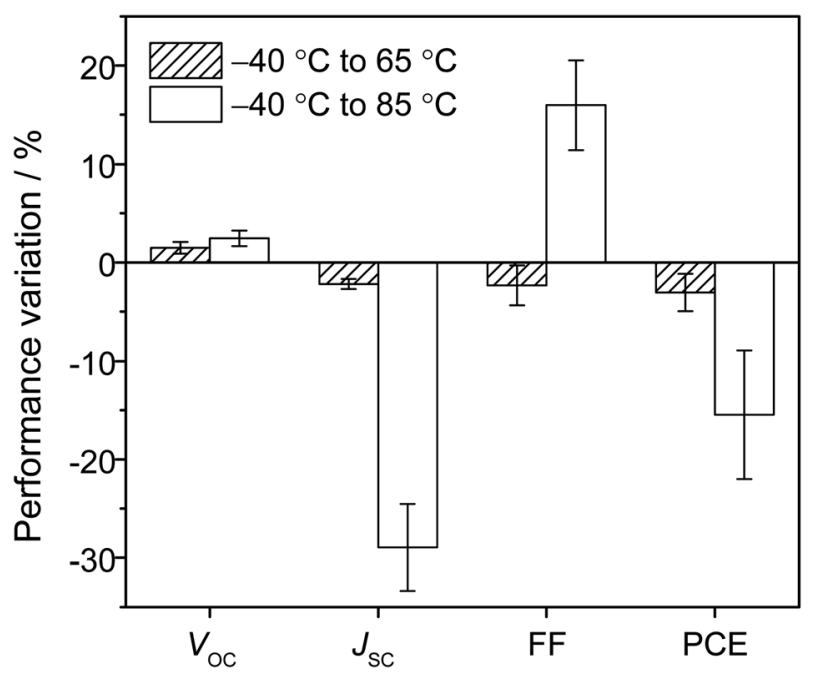

Fig. 9 Performance variation of devices after thermal cycling tests of $-40{ }^{\circ} \mathrm{C}$ to $65^{\circ} \mathrm{C}$ and of $-40{ }^{\circ} \mathrm{C}$ to $85^{\circ} \mathrm{C}$. 


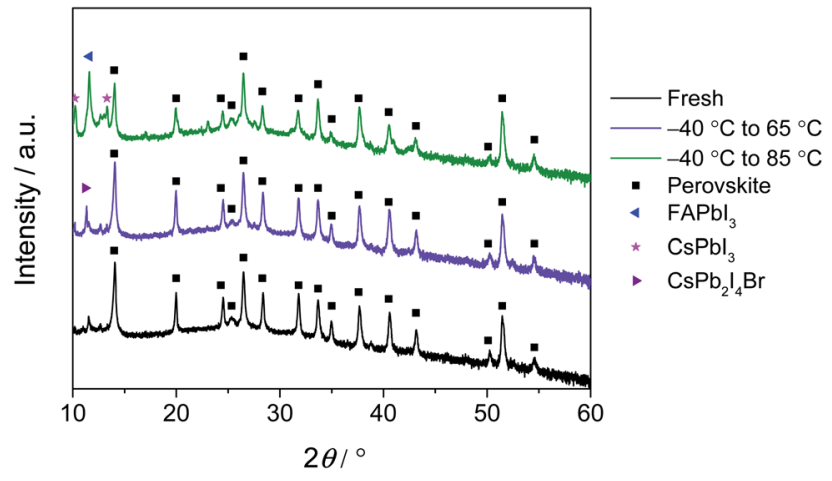

Fig. $10 \mathrm{XRD}$ pattern for a fresh device vs. hermetic encapsulated devices after 50 cycles of $-40{ }^{\circ} \mathrm{C}$ to $65^{\circ} \mathrm{C}$ and of $-40{ }^{\circ} \mathrm{C}$ to $85^{\circ} \mathrm{C}$.

indicates perovskite decomposition due to humidity (i.e. reaching up to $85 \% \mathrm{RH}$ ) - Fig. S9 and S10.†

\section{Conclusions}

Hermetic encapsulation is a critical feature for improving the long-term stability of PSC devices. A suitable airtight encapsulation effectively prevents moisture and oxygen related degradation concerns of PSCs. Conventional PSCs are fabricated with temperature sensitive HTLs and the previously reported laserassisted glass frit sealing technique cannot be used to encapsulate these types of devices due to high process temperature and long dwell times. In the present work, a novel laser-assisted glass frit encapsulation method was developed that can be used to hermetically encapsulate HTL-based conventional PSCs. The technique uses a dual laser beam configuration where one laser beam preheats the glass frit material from $50{ }^{\circ} \mathrm{C}$ up to $110 \pm 10$ ${ }^{\circ} \mathrm{C}$, while the other laser beam melts the glass frit and bonds the glass substrates.

A dynamic phenomenological 3D model was developed, validated and used to analyze and optimize the dual laser beam glasssealing process. Using two laser beams, the simulation results indicate a thermal stress decrease of $c a$. 9.1\%, during the lasersealing process, when compared with laser-sealing with a single laser beam, for a process temperature of $50{ }^{\circ} \mathrm{C}$. Furthermore, the thermal stress decreases by $c a .13 .8 \%$ by reducing the thickness of glass substrates from $2.2 \mathrm{~mm}$ to $1.1 \mathrm{~mm}$.

The PSC layers were deposited $4 \mathrm{~mm}$ away from the glass frit sealant, and the maximum temperature recorded at the center of the device was $65 \pm 5{ }^{\circ} \mathrm{C}$ for $60 \mathrm{~s}$. The dual laser-sealing process caused no notable performance losses in PSC devices fabricated with PTAA as the HTL.

Hermitically encapsulated devices submitted for 500 hours to humid air exposure at $85 \% \mathrm{RH}$ showed no performance losses, while non-hermetic devices displayed 50\% of PCE loss after $200 \mathrm{~h}$. XRD analysis showed the presence of $\mathrm{Pb}$ halides, associated with moisture induced decomposition of the perovskite absorber, in the non-hermetically encapsulated devices. In contrast, no evidence of $\mathrm{Pb}$ halides was found in the devices hermetically sealed.
The long-term stability of the encapsulated PSC devices was further tested according to the thermal cycling test of the IEC 61215 standard. The tested devices show a PCE loss of $c a .16 \%$. This loss of performance was assigned to the temperature sensitivity of the HTL (PTAA) since no perovskite decomposition was observed in the $\mathrm{XRD}$ patterns. A moderate thermal cycling test between $-40{ }^{\circ} \mathrm{C}$ and $65{ }^{\circ} \mathrm{C}$ showed a minor PCE drop of $3.4 \%$.

The present study highlights that the hermeticity level of the encapsulation is the most crucial step for achieving external environmental stability of PSCs towards humidity and oxygen ingress. For the first time ever a very robust and hermetic glass encapsulation process is disclosed, using a process temperature compatible with all types of state-of-the-art PSC devices.

An advanced dual laser beam sealing process was developed to encapsulate temperature sensitive HTL-based PSCs, which provided long-term stability towards humidity and moderate thermal cycling tests. The present research points out that further advancements on thermally stable HTL materials are essential to grant the long-term thermal stability of PSCs according to the IEC 61215 standard. The combination of the present encapsulation and thermally stable materials will ensure successful commercialization of perovskite solar cells.

\section{Conflicts of interest}

There are no conflicts to declare.

\section{Acknowledgements}

J. Martins, S. Emami and R. Madureira are grateful to the Portuguese Foundation for Science and Technology (FCT) for their PhD grants (references: SFRH/BD/147201/2019, SFRH/BD/ $119402 / 2016$ and SFRH/BD/137782/2018). This work was partially supported by the European Union's Horizon 2020 Programme, through a FET Open research and innovation action under grant agreement no. 687008. The authors also acknowledge the projects: (i) POCI01-0145-FEDER-006939, funded by the European Regional Development Fund (ERDF), through COMPETE 2020 - Programa POCI and by nationals funds through FCT and (ii) POCI-01-0247-FEDER-017796, "WinPSC" co-funded by ERDF, through COMPETE 2020, under the PORTUGAL 2020 Partnership Agreement. This work was financially supported by: Base Funding - UIDB/00511/2020 of the Laboratory for Process Engineering, Environment, Biotechnology and Energy - LEPABE - funded by national funds through the FCT/MCTES (PIDDAC). Part of this work was also performed under the projects (i) SunStorage "Harvesting and storage of solar energy", with reference POCI01-0145-FEDER016387, and (ii) Sunflow "Solar energy storage into redox flow batteries” with reference PTDC/EQUEQU/30510/2017 - POCI-010145-FEDER-030510, funded by (ERDF), through COMPETE 2020 - (OPCI), and by national funds, through FCT.

\section{References}

1 NREL, Best Research-Cell Efficiencies, available from: https://www.nrel.gov/pv/cell-efficiency.html. 
2 A. Kojima, et al., Organometal Halide Perovskites as VisibleLight Sensitizers for Photovoltaic Cells, J. Am. Chem. Soc., 2009, 131(17), 6050-6051.

3 T. Leijtens, et al., Stability of Metal Halide Perovskite Solar Cells, Adv. Energy Mater., 2015, 5(20), 1500963.

4 M. I. Asghar, et al., Device stability of perovskite solar cells a review, Renew. Sustain. Energy Rev., 2017, 77, 131-146.

5 J. A. Christians, P. A. Miranda Herrera and P. V. Kamat, Transformation of the Excited State and Photovoltaic Efficiency of $\mathrm{CH}_{3} \mathrm{NH}_{3} \mathrm{PbI}_{3}$ Perovskite upon Controlled Exposure to Humidified Air, J. Am. Chem. Soc., 2015, 137(4), 1530-1538.

6 A. Farooq, et al., Spectral Dependence of Degradation under Ultraviolet Light in Perovskite Solar Cells, ACS Appl. Mater. Interfaces, 2018, 10(26), 21985-21990.

7 T. A. Berhe, et al., Organometal halide perovskite solar cells: degradation and stability, Energy Environ. Sci., 2016, 9(2), 323-356.

8 H.-S. Kim, J.-Y. Seo and N.-G. Park, Material and Device Stability in Perovskite Solar Cells, ChemSusChem, 2016, 9(18), 2528-2540.

9 D. Wang, et al., Stability of perovskite solar cells, Sol. Energy Mater. Sol. Cells, 2016, 147, 255-275.

$10 \mathrm{H}$. Greenhouse, R. Lowry and B. Romenesko, Hermeticity of Electronic Packages, Elsevier Inc, Oxford, 2012.

11 S. Emami, et al., Advanced hermetic encapsulation of perovskite solar cells: the route to commercialization, $J$. Mater. Chem. A, 2020, 8(5), 2654-2662.

12 MIL-STD-883H, Test method standard microcircuits, 2010, United States Department of Defense.

13 M. V. Khenkin, et al., Consensus statement for stability assessment and reporting for perovskite photovoltaics based on ISOS procedures, Nat. Energy, 2020, 5(1), 35-49.

14 IEC61215, Terrestrial photovoltaic (PV) modules - Design qualification and type approval, 2016.

15 F. Matteocci, et al., Encapsulation for long-term stability enhancement of perovskite solar cells, Nano Energy, 2016, 30, 162-172.

16 R. Cheacharoen, et al., Encapsulating perovskite solar cells to withstand damp heat and thermal cycling, Sustainable Energy Fuels, 2018, 2(11), 2398-2406.

17 D. K. Ivanou, et al., Laser assisted glass frit sealing for production large area DSCs panels, Sol. Energy, 2016, 135, 674-681.

18 R. Knechtel, Glass frit bonding: an universal technology for wafer level encapsulation and packaging, Microsyst. Technol., 2005, 12(1-2), 63-68.

19 R. Knechtel, Glass Frit Wafer Bonding, in Handbook of Wafer Bonding, 2012, pp. 1-17.
20 M. Esashi, Wafer level packaging of MEMS, J. Micromech. Microeng., 2008, 18(7), 073001.

21 N. Lorenz, et al., Hermetic glass frit packaging in air and vacuum with localized laser joining, J. Micromech. Microeng., 2011, 21(4), 045039.

22 R. M. Morena, et al., Frit Sealing of OLED Displays, in Handbook of Organic Light-Emitting Diodes, 2018, pp. 1-22.

23 F. Ribeiro, et al., Laser assisted glass frit sealing of dyesensitized solar cells, Sol. Energy Mater. Sol. Cells, 2012, 96, 43-49.

24 R. Sastrawan, et al., A glass frit-sealed dye solar cell module with integrated series connections, Sol. Energy Mater. Sol. Cells, 2006, 90(11), 1680-1691.

25 A. K. Jena, et al., Role of spiro-OMeTAD in performance deterioration of perovskite solar cells at high temperature and reuse of the perovskite films to avoid $\mathrm{Pb}$-waste, $J$. Mater. Chem. A, 2018, 6(5), 2219-2230.

26 M. Saliba, et al., Incorporation of rubidium cations into perovskite solar cells improves photovoltaic performance, Science, 2016, 354(6309), 206-209.

27 K. Domanski, et al., Not All That Glitters Is Gold: MetalMigration-Induced Degradation in Perovskite Solar Cells, ACS Nano, 2016, 10(6), 6306-6314.

28 I. Mesquita, L. Andrade and A. Mendes, Temperature Impact on Perovskite Solar Cells Under Operation, ChemSusChem, 2019, 12(10), 2186-2194.

29 S. Emami, et al., Low temperature hermetic laser-assisted glass frit encapsulation of soda-lime glass substrates, Opt. Laser Eng., 2017, 96, 107-116.

30 S. Emami, et al., Development of hermetic glass frit encapsulation for perovskite solar cells, J. Phys. D: Appl. Phys., 2019, 52(7), 074005.

31 T. L. Bergman, et al., Fundamentals of Heat and Mass Transfer, Wiley, 2011.

32 T. R. Hsu, The Finite Element Method in Thermomechanics, Springer, Netherlands, 2012.

33 Y. Zhang, et al., Solution-Processed Transparent Electrodes for Emerging Thin-Film Solar Cells, Chem. Rev., 2020, 120(4), 2049-2122.

34 T. S. Sherkar, et al., Recombination in Perovskite Solar Cells: Significance of Grain Boundaries, Interface Traps, and Defect Ions, ACS Energy Lett., 2017, 2(5), 1214-1222.

35 M. B. Johnston and L. M. Herz, Hybrid Perovskites for Photovoltaics: Charge-Carrier Recombination, Diffusion, and Radiative Efficiencies, Acc. Chem. Res., 2016, 49(1), 146-154.

36 R. Cheacharoen, et al., Design and understanding of encapsulated perovskite solar cells to withstand temperature cycling, Energy Environ. Sci., 2018, 11(1), 144150. 